\title{
M.Ö.13.Yüzyılda Kargamıš Krallığında Görevli İki Hitit Memuru: mâr šarri (DUMU.LUGAL) ve ${ }^{L \mathscr{U}}$ kartappu
}

\author{
Two Hittite offıcials commissioned in the Kargamıš Kingdom \\ during 13th Century B.C.
}

\section{İlknur TAŞ}

\section{$\ddot{O} z$}

M.Ö.13. yüzyllda Kargamıš Krallı̆̆l, Hitit Devleti'nin Suriye'deki en önemli vassali ayn zamanda da Suriye'deki Hitit yönetiminin merkeziydi. Hitit Devleti'nin Suriye'de hakim olduğu bölgeler üzerinde, Kargamıš kralı doğrudan doğruya kontrol yetkisine sahiptir. Bu çağda iletişimin yavaşllğından ve Hitit bölgesinin merkezinden dışarı olan hareketlerin klş aylarında sert bir şekilde engellenmesi gerçeğinden hareketle; Hitit idari sistemini Suriye'de birebir uygulamak amactyla, Kargamıš Krallı̆̆g'na IV.Tudhaliya tarafindan çok sayıda üst düzey memur atanmuştır. Kendilerine yüksek payeler verilmiş Suriye-Hitit bürokrasisinin içinde değerlendirilmesi gereken bu görevlilerden, belgelerde en sık adı geçenler mâr šarri (DUMU.LUGAL) ve ${ }^{L U}$ kartappu unvanl görevlilerdir. Hattuša, Ugarit ve Emar'dan ele geçen belgelere göre, söz konusu görevlilerin çoğunlukla Hitit kralı tarafindan, özel olarak politik ve idari görevleri gerçekleştirmek için Suriye'ye gönderildikleri anlaşılmaktadır. Söz konusu görevlilerin, günümüzde devletlerin dış politikaları konusunda donanımlı büyükelçiler ile karşılaştırabileceğini düşünüyoruz.

Anahtar kelimeler: Hitit Devleti, Hitit Memurlarl, IV.Tudhaliya, Kargamıš, Ugarit, Suriye.

\footnotetext{
Abstract

In the $13^{\text {th }}$ century B.C. Kargamıš Kingdom was the most important vassal and the center of Hittite administration in Syria. Kargamıs King had the direct controling authority on the Syrian section of Hittite State. In view of slower communications and the diffucult travel conditions in and out of the Hittite central
}

* Dr., Hitit Üniversitesi, Fen-Edebiyat Fakültesi, Tarih Bölümü, Öğretim Görevlisi. 
during Winter season, a large number of high ranking officials were appointed by King Tudhaliya IV to the Kargamıš Kingdom so as to impliement Hittite administrative system in Syria. Among Syrian-Hittite high ranking bureaucracy, the most frequent officials are those with the title mâr šarri (DUMU.LUGAL) and ${ }^{L U}$ kartappu. According to documents discovered in Hattuša, Ugarit and Emar, these officials were offen appointed by the Hittite King with special political and administrative missions in Syria. These missions can be compared to the rank of ambassador experienced in administaring foreign policies of contemporary states.

Keywords: Hittite State, Hittite Officials, Tudhaliya IV, Kargamı̌̌, Ugarit, Syria.

Hitit idari sisteminde çok sayıdaki yüksek dereceli memur doğrudan Hitit büyük kralına karşı sorumluydu ve düzenli olarak büyük krala rapor vermek zorundaydılar. ${ }^{1}$ Memurlar, Hitit idare sisteminin en mühim ve yaygın, sayıca da en fazla olan yürütücüleriydi. Memuriyet sadece mülki idarede değil, dini ve askeri işlerde de söz konusuydu. ${ }^{2}$ Hitit memurları, en yüksek rütbeli idareciler ve askeri görevlilerden, nispeten düşük sayabileceğimiz görev sahiplerine kadar uzanan bir silsileyi takip etmekteydiler. Söz konusu memurların büyük kralla ilişkileri, resmi görevleri ve yükümlülükleri oldukça ayrıntılı olarak düzenlenen "Direktif Metinleri" ile belirlenirdi. ${ }^{3}$ Merkezi devleti temsil eden kral ile memurlar arasındaki idari işleri düzenleyen, prensiplere bağlayan en yaygın organ buyruklar ya da direktiflerdir. Bu belgelerin tümünde, Hitit büyük kralının hizmetinde olan görevlilerin, günlük etkinliklerine ve faaliyetlerine ilişkin değerli bilgiler verilmektedir. Söz konusu çalışmamızda, özellikle Ras-Şamra (Ugarit) belgelerinde ${ }^{4}$ adlarından sıklıkla söz edilen ve sorumlu oldukları bölgede

\footnotetext{
${ }^{1}$ Starke, 1996, 143 vd.; Imparati, 1983, 225 vd; Daddi, 1982; von Schuler, 1957.

2 Ünal, 2005, $110 \mathrm{vd}$.

3 Bugüne dek sınır beylerine (auriiaš išha- BEL MADGALTI), IV.Tudhaliya'nın oldukça yüksek bir makam olan "başkan”lara ( ${ }^{\text {LÚ.MEŠ }} \mathrm{SAG}$ ), rahipler ve tapınak görevlilerine, belediye başkanlarına (HAZANNU), Muhafız kıtası askerlerine (MEŠEDI) gönderilen direktif metinleri elimize geçmiştir. Ünal, 2005, 118-124; McMahon, 1997, 217-230; Reyhan, 1994; Güterbock-van den Hout, 1991, 4 vd.; Süel, 1985; Daddi, 1975, 93-136; Otten, 1964, 91-95; von Schuler, 1957; Jacob-Rost, 1965, 165 vd; Goetze, 1950, 207-210; Alp, 1947, 383 vd; Sturtevant-Bechtel, 1935, 127-174.

${ }^{4}$ Ras-Şamra'da (Ugarit) yapılan kazılar sonucunda, çoğunluğu Akadca ve Ugaritce kaleme alınmış çivi yazılı birkaç bin kil tablet gün ışığına çıkarılmıştır. Bu belgeler arasında, Sumerce ve Hurrice çivi yazılı tabletler, Hiyeroglif Mısırcası ile yazılmış metinler de açı̆̆a çıkarılmıştır. Söz konusu belgelerin büyük bir kısmı, saray ve civarında kazılan arşivlerde bulunmuştur. Ayrıca V avlusundaki bir fırında bir çok tablet bulunmuştur. Bunun dışında Rashap-abu ve Rap'anu isimli kişilere ait olduğu düşünülen saray civarındaki özel mülklerde de gün 1 şı̆ğına çıkarılmış arşivler bulunmuştur. Kentin güney kısmında ise, Hurrili bir rahibe ait belgeler gün ışığına çıkarılmıştır. Ras-Şamra'da yapılan kazı çalışmaları sonucunda açığa çıkartılan belgeler, Suriye'deki diğer merkezlerde açığa çıkarılan belgeler arasında en önemli
} 
Hitit kralının talimatlarını en iyi şekilde yerine getirmek için çalışan, görev yaptıkları sahalar ve üstlendikleri sorumluluklar itibarıyla Hitit Devleti için büyük önem teşkil eden iki idari memur mâr šarri (DUMU.LUGAL) ve ${ }^{L U}$ kartappu'yu ele alacağız.

\section{1. mâr šarri (DUMU.LUGAL) ve Görevleri}

M.Ö. 13. yüzyılda Kargamıš'ta Hitit kralı I.Šuppiluliuma'nın soyundan gelen bir hanedanlık görev yapmaktayd ${ }^{5}{ }^{5} \mathrm{Bu}$ dönemde Kargamıš, Suriye'deki en önemli politik güç haline gelmiştir. Kargamıš Krallığı'nın Suriye'deki diğer Ugarit ve Amurru gibi Hitit Devleti'ne bağlı vassal krallıklar ile karşılaştırıldığında Hitit kralı nezrinde çok daha önemli ve özel bir yeri vardır. Suriye topraklarının idaresinin, bu toprakların savunması da dahil olmak üzere bu devirde, Kargamıš Kralı tarafından üstlenildiği anlaşılmaktadır. M.Ö. 13. yüzyıla ait Mısır yazıtlarında Kuzey Suriye "Kargamıš Ülkesi" olarak anılmaktadır. ${ }^{6}$ Bu önemli bilgi de, M.Ö. 13. yüzyılda Kargamıš Krallığı'nın Hitit Devleti'nin Suriye'de idare ettiği kısmı üzerindeki hakimiyetini kanıtlamaktadır. ${ }^{7}$ M.Ö. 13. yüzyılın başından itibaren Kargamıš, Suriye'de Hititler'in hakimiyeti altındaki toprakların büyük bölümüne hükmeden merkezileşmiş bir idare sistemi geliştirmiştir. Buna göre Kargamıs’ta Hititli yöneticilerin idaresi altında, tamamıla imparatorluk topraklarına entegre edilmiş (Mukiš ${ }^{8}$ gibi) bölgelerin veya

olanlarıdır. Ras-Şamra arşivlerinde gün ışı̆̆ına çıkarılan ve geç bronz çağına ait diğer yerleşimlerden gelen verilerle eksik kısımları tamamlanan söz konusu belgelerin, kentin M.Ö. 1350 ile M.Ö. 1200 yılları arasındaki politik tarihini aydınlattığını söylemek mümkündür. Klengel, 1992, 100 vd., 130 vd.

5 I.Šuppiluliuma'nın Kargamıš'1 ele geçirmesiyle birlikte (M.Ö. 1352) Suriye'de yeni bir dönem başlamıştır. I.Šuppiluliuma oğullarından biri olan Piyašili'yi (Hurrice ismi ŠarriKušuh) Kargamıš kralı olarak tayin etmiştir. (KUB XIX 9 I st.17 vd., CTH 83, KBo VI 28 st.19 vd., CTH 88) Piyašili (Šarri-Kušuh), M.Ö.12.yüzyılın başlarına kadar en az beş jenerasyon boyunca hüküm süren Kargamıš Krallı̆̆ı'nın bir anlamda kurucusu olmuştur. Piyašili'den sonra sırasıyla, Šahurunuwa, İni-Tešub, Talmi-Tešub ve Kuzi Tešub Kargamıš’ta hükümdarlık yapmışlardır. Liverani, 1960, 135-147; Klengel, 1965, 51-101; Hawkins, 1980, 429-434.

${ }^{6}$ Klengel, 1992, 125 dn.198; Klengel, 1965, 69 vd.

${ }^{7}$ Bu konu hakkındaki detaylı bilgi ve bibliyografya için bkz. Taş, 2007, 94-131.

${ }^{8}$ Eskiden Halep Krallığı'nın parçası olan Mukiš, Hitit kralı I.Muršili tarafından krallığın tahrip edilmesinden sonra, Mitanni kontrolüne girmiş ve Mitanni kralı Parattarna tarafından vassali olan İdrimi'ye tahsis edilmiştir. Sonraları, I.Suppiluliuma'nın birinci yılında yaptığı Suriye seferleri esnasında tekrar fethedilmiştir. Bununla birlikte, içlerinde Niya ve Nuhašše'nin de yer aldığı Hitit karşıtı birkaç Kuzey Suriye Krallığı ile koalisyon yaparak Hitit egemenliğinden kurtulmak istemiş; ancak söz konusu isyan, bir Hitit seferi ile bastırılmıştır. Daha sonra Mukiš ve Niya'nın önemli bir bölümü, Hitit Devleti ile bizzat müttefik olan ve isyancı birliğe katılmayı reddeden Ugarit kralı II.Niqmaddu'ya devredilmiştir. Ugarit'in kuzeyine yerleştirilen Mukiš yerleşiminin, daha sonra Kargamıš Krallığı'nın bir parçası haline 
doğrudan Kargamıš tarafından kontrol edilen vassal krallıkların etrafında birleştiği merkezi bir yönetim sisteminin söz konusu olduğu anlaşılmaktadır. Kargamıš kralı, bu bölgede doğrudan doğruya Hitit büyük kralı adına kontrol yetkisine sahiptir. Kargamıš kralı İni-Tešub'un Hititler'in Suriye'deki temsilcisi sıfatıyla gerçekleştirdiği eylemleri en iyi Ugarit kralları II.Ammištamru ve Ibiranu dönemlerine tarihlenen Ugarit belgelerinden öğreniyoruz. ${ }^{9}$ Kargamıš kralı İni-Tešub, Ugarit'te bulunmuş bir çok hukuki, idari ve politik belgeyi Hitit kralı IV. Tudhaliya ile birlikte mühürlemiştir. ${ }^{10}$ Kargamıš kralı İni-Tešub bu devirde gerçekleştirilmiş davaların büyük bir bölümünde yer almıştır. ${ }^{11}$ Ini-Tešub'un Kargamıš Krallığı yaptığı dönem aslında, Hitit İmparatorluğu'nun yoğun baskı altında bulunduğu bir devri yansıtmaktadır. Aynı tarihte Hitit kralı IV. Tudhaliya'nın, ülkenin batısındaki gelişmeler karşısında askeri tedbir almakla meşgul olduğu anlaşılmaktadır. Bu yüzden, Suriye'deki vassal krallıklar arasındaki sorunları çözümlemek ve onların her türlü hukuki davasıyla bizzat ilgilenmek, Kargamıš kralı İni-Tešub'un en önemli görevi olmuştur. Kargamıš kralı, Hitit kralının olmadığı yerde veya Hitit kralının çeşitli nedenlerle gelemediği herhangi bir davada kralın yerini almaktayd ${ }^{12}{ }^{2}$ Suriye vassal krallıkları arasındaki her türlü uzlaşmazlıkta ve davalarda Hitit kralından sonra yetkili kişi Kargamıš kralı idi. ${ }^{13}$

Bu çağda iletişimin yavaşlığından ve Hitit bölgesinin merkezinden dışarı olan hareketlerin özellikle zorlu kış şartlarında engellenmesi gerçeğinden hareketle, Hitit Kralı'nın Suriye'de oluşturduğu bu idari sistem, bizzat kendisi tarafından Suriye'ye gönderilen ve kendilerine yüksek yetkiler verilmiş memurlar tarafından idare edilmekteydi. ${ }^{14}$ Ugarit'te gün 1şığına çıkarılan belgelerde mâr šarri, Hititçe belgelerde ise DUMU.LUGALunvanıla yer alan memurlar belgelerde en sık adı geçenlerdir. DUMU.LUGAL "kral oğlu, prens" anlamına gelmekte olup; akadcası mar šarri, hititcesi ise bilinmemektedir. ${ }^{15}$ Hitit kralları tarafından yüksek dereceli memurlara gönderilen ve yukarıda kısaca bahsettiğimiz "Direktif Metinleri" içerisinde bazı durumlarda DUMU.LUGAL "kral oğlu,

geldiği görülmektedir. Bryce, 2003, 140-141; Klengel, 1992, 123 dn.190.

${ }_{9}^{9}$ Hawkins, 1980, 431-433; Klengel, 1965, 63-67; Nougayrol, 1956; Nougayrol, 1955.

10 İni-Tešub uzun saltanat dönemi sırasında beş farklı mühür kullanmıştır: İki damga mühür ve üç tane silindir mühür. Damga mühürler, Hitit büyük krallarının kullanmış oldukları geleneksel Hitit mühür modeline benzemektedir. Silindir mühürler ise, tipik Suriye geleneğinin bir ifadesidir. D’Alfonso, 2001, 269.

${ }_{11}$ Taş, 2007a, 113-126; Hawkins, 1980, 431.

12 Taş, 2007b, 104 dn. 418.

${ }^{13}$ Taş, 2007b, 103 vd.; Starke, 2001, 282; Hawkins, 1980, 431.

${ }^{14}$ Taş, 2007b, $103 \mathrm{vd}$.

${ }^{15}$ Friedrich, 1952, 269. 
prens"lere yönelik maddeler bulunmaktadır. Söz konusu metinlerden anlaşıldığına göre bir kral oğlu nadir de olsa kralın yerine ordunun başına geçebilirdi. Bu durumda ona esas kral gibi itaat edilirdi. ${ }^{16}$ LUU $^{\mathrm{MEŠ}}$ SAG'lar "saray memurları" için verilen direktiflerden anlaşıldığına göre DUMU.LUGAL ${ }^{\mathrm{MEŠ}}$ "kral oğulları" kralın temsilcisi olarak bir yabanc1 ülkeye gidebilirlerdi. ${ }^{17}$ Bazı hukuki belgelerde, DUMU.LUGAL unvanına sahip kişiler tanık listelerinde şahit olarak bulunmaktadırlar. ${ }^{18}$ Elimizdeki bazı kült metinlerinde ise, bir DUMU.LUGAL bizzat kült törenini yönetmektedir. $^{19}$ Eğer Hititce metinlerde DUMU.LUGAL hiyerarşi içerisinde kral ve kraliçeden hemen sonra geliyorsa muhtemelen esas ve gerçek oğludur. Nitekim dini metinlerin büyük bir kısmında DUMU.LUGAL'in kraldan doğma bir prens olduğu tahmin edilmektedir. ${ }^{20}$

Hitit idari kadrosunun bu yüksek kademesinin kraliyet soyundan kişiler tarafından temsil ediliyor olabileceği anlamı çıktığı halde, bu unvanı taşıyanların hepsinin saltanattaki büyük kralın soyundan olmadıkları çok açıktır. ${ }^{21}$ Bu unvan aynı dönemde pek çok kişiye verilmiş olup, bunların hepsinin birden büyük kralın oğlu olması çok zor bir ihtimaldir. Bu unvan ile kimi zaman belgelerde bir kralın oğlundan çok belirli yüksek bir memur da ifade edilmek istenmiştir. ${ }^{22}$

Hattuša, Ugarit ve Emar'dan ele geçen belgeler, DUMU.LUGAL ya da mâr šarri'lerin çok yüksek sınıftan görevliler olduklarını göstermektedir; onlar sık sık Hitit kralı tarafından, özel olarak politik ve idari görevleri gerçekleştirmek için Suriye'ye gönderilmekteydiler. Mâr šarri’ler anlaşıldığına göre, sürekli olarak aynı bölgede görevlendirilmezlerdi. Kargamıš'ta ve Ugarit'te devletin problemli sınırlarını çözmeye giden, kraliçe ve vergi memuru arasında hakemlik yapan ve hatta Ugarit kralı Ibiranu'nun efendisi büyük kralın huzuruna çıkması gerektiğinde düzenlemeyi yapan mâr šarri' ler ile karşılaşıyoruz. ${ }^{23}$ Genel olarak bu unvanı

\footnotetext{
${ }^{16}$ KUB XIII 20'de eğer kral askeri bir savaşa katılmazsa orduyu bir DUMU.LUGAL veya BELU GAL'e teslim etmektedir. Alp, 1947, $383 \mathrm{vd}$.

${ }^{17}$ von Schuler, 1957,13 vd.

${ }^{18}$ KBo IV 10 (Ulmi-Tešub Antlaşması) Rs. 28-31.satırlarda DUMU.LUGAL unvanıyla yer alan tanıklar sırasıyla şunlardır: Hannutti, Huzziya, İni-Tešub, Hešni, Tattamaru, Upparamuwa, Šahurunuwa, Šarruma- ${ }^{\mathrm{d}}$ LAMMA, van den Hout, 1995, 48-49; Imparati, 1974, 36.

${ }^{19}$ KUB XX 7, KUB XX 45, KUB XX 80, KUB XX 81, KUB XX 88, KUB XXV 36, KUB XXVIII 90, KUB XXXIV 128, (CTH 647).

${ }^{20}$ Imparati, 1975, 93.

${ }^{21}$ Beckman, 1992, 47.

${ }^{22}$ Beckman, 1995, 28; Imparati, 1975, 80-95.

23 Emar belgelerinde mâr šarri’ler çok sıklıkla gayrimenkul ve kölelerle ilgili çeşitli davalarda tanık olarak bulunmaktadır. Bu görevliler her seferinde bu belgelerin tanık
} 
taşıyan kişilerin Kargamıš kralı İni-Tešub, Ugarit kralları Ibiranu ve II.Ammištamru döneminde, Hitit idaresi altındaki Suriye Krallıkları üzerinde uygulanan gözetim ve denetim görevi açısından, son derece önemli ve etkin oldukları kabul edilmektedir. ${ }^{24}$ Söz konusu görevliler gittikleri bölgede yargıçlık ve şahitlik de yapmaktaydılar. ${ }^{25}$

III. Hattušili ve IV. Tudhaliya Devri'ne tarihlenen pek çok belgede adı geçen mâr šarri’lerden biri olan Arma-ziti, aynı zamanda önemli dini görevler üstlenmiş bir yazmandır. ${ }^{26}$ Ugarit belgeleri içinde bazı adli kararların altında Kargamıš kralı İni-Tešub veya onun oğlu ve ardılı olan Talmi-Tešub yerine, Arma-ziti'nin isminin olduğu göze çarpmaktadır. Bu şahıs bazı sınır anlaşmazlıkları sonrasında Ugarit sınırlarını tekrar eski haline getiren kişi olarak karşımıza çıkmaktadır. ${ }^{27}$ Arma-ziti'nin, Kargamıš ile Hitit Krallıkları arasında üstlenmiş olduğu görevi ve onun sorumluluk alanını anlayabilmek için burada kendisinin de adı geçtiği bazı belgeleri ele almak isteriz. Söz konusu belgelerden ilki Kargamıš kralı tarafından Ugarit kralı Ibiranu'ya gönderilmiş bir mektuptur ${ }^{28}$. Belgede Kargamıš kralının adı yer almamaktadır. Bu dönemde mevcut yazılı belgelerde, Kargamıš krallarından isimleriyle bahsedilmemiş olması son derece dikkat çekici bir durumdur. Bununla birlikte Ugarit kralı Ibiranu'nun hükümdarlığının ilk evresinin, Kargamıš kralı İni-Tešub'un hükümdarlığıyla aynı zamana denk düştüğünü bilmekteyiz. Bu tarihte Kargamıš ile Ugarit arasındaki yakın ilişkilerin devam ettiği anlaşılmaktadır. Mektubun ilk satırlarında, Ugarit Krallığı'na ait sınırların Arma-ziti tarafından tayin edildiğine işaret edilmektedir. Söz konusu kısmın tercümesi şöyledir: RS $17.292^{29}$

1-4 Kargamıš kralı, Ugarit kralı Ibiranu'ya şöyle (der):

5 Selamlar!

5-11 Sınırlarınla ilgili olarak bana yazdığın meseleye gelince, Armaziti'nin belirlemiş olduğu bütün sınırlarını ben düzenleyeceğim.

Daha sonra Kargamıš ve Ugarit sınırındaki sınır tecavüzlerinden bahsedilmektedir. Bu mesele ile ilişkili olarak Kargamıš kralının, mâr šarri

listelerinin en başında yer almaktadırlar; bu da onların büyük kralın nezrinde de önemli bir pozisyonda olduklarına işarettir. Beckman, 1992, 47.

${ }^{24}$ Imparati, 1987, 191.

${ }^{25}$ RS 17.314, Nougayrol, 1956, 189.

${ }^{26}$ Imparati, 1988, 79 vd; Imparati, 1987, 197 vd.

${ }^{27}$ Drower, 1968, 17.

${ }^{28}$ RS 17.292, Nougayrol, 1956, 188. Paralel Metinler: RS 15.77, Nougayrol, 1955, 6-7; RS

17.78, Nougayrol, 1956, 196-197.

${ }^{29}$ RS 17.292, Nougayrol, 1956, 188. Paralel Metinler: RS 15.77, Nougayrol 1955, 6-7; RS

17.78, Nougayrol, 1956, 196-197. 
Ali-hešni ve mâr šarri Arma-ziti’yi sınırlarla ilişkili bir takım düzenlemeler yapmak üzere bölgeye gönderdiği ifade edilmektedir. Arma-ziti ise, talimatlara uygun şekilde, Ugarit'teki sınır sorunlarını çözmekle ve sınırları yeniden belirlemekle yükümlü iki resmi görevli Ebina ' $e^{30}$ ve Kurkalli ${ }^{31}$,yi bölgeye gönderdiğini krala bildirir. Söz konusu kısmın tercümesi şöyledir: RS $17.292^{32}$

15-18 Ben Ebina 'e ve Kurkalli’yi hemen gönderdim

19-21 Onlar sınırları araştırıp senin için belirleyecekler.

Sorunlu sınırın belirlenişi ve yeni düzenlemenin nedeni ve boyutu bilinmemektedir. Ancak bu mektubun tamamen benzeri bir başka mektup, bu kez mâr šarri Ali-hešni ${ }^{33}$ tarafından Ugarit kralı Ibiranu'ya gönderilmiştir. Ayrıca yukarıda adı geçen ve sınırları tespit etmekle görevli Ebina'e'nin bizzat kendisi, Ugarit kralına yönelik bir başka mektup göndermiştir. ${ }^{34} \mathrm{Bu}$ mektuplardan hiçbirisi sorunlu olan sınıra gönderme yapmaz. Ancak bu dönemde en çok sorunların yaşandığı iki sınır bölgesi vardır: Mukiš ve Šiyannu. Büyük olasılıkla söz konusu sınır kenti Šiyannu olmalıdır. ${ }^{35}$ Geçmişte Ugarit ve Šiyannu arasında yine sınırlarla ilgili anlaşmazlıklar yaşanmıştır. ${ }^{36}$ Sonuç olarak, Ibiranu'nun saltanatı sırasında tekrar gündeme gelen bu konu, muhtemelen Arma-ziti'nin uriyannu $^{37}$ aracılığıyla sınırları sabitlemesiyle çözüme kavuşturulmuş ve iki görevli Ebina ‘e ve Kurkalli onları işaretlemek üzere gönderilmiștir. Arma-ziti'nin resmi sıfatı belgelerde ifade edilmediği halde, ${ }^{38}$ genellikle kuş fallarına (kehanet soruları) çok sık katılmaktaydı.

\footnotetext{
${ }^{30} \mathrm{Bu}$ isim kırık bir hiyeroglif mühür baskısı üzerinde de yer almaktadır. Singer, 1999, $685 \mathrm{dn}$. 272.

31 Bir Hitit ritüelinin betimlendiği küçük bir tablet parçasında (KUB XLVIII 113 st.5) Kargamıš sarayıyla bağlantılı bir Gur-ga-li-eš geçmektedir. Klengel, 1965, 66.

${ }^{32}$ RS 17.292, Nougayrol, 1956, 188. Paralel Metinler: RS 15.77, Nougayrol, 1955, 6-7; RS 17.78, Nougayrol, 1956, 196-197.

${ }^{33}$ Hitit kaynaklarında yer alan Ali-hešni adı için bkz. Imparati, 1974, 115-116; Imparati, 1987, 196-197.

${ }^{34}$ RS 17.78, Nougayrol, 1956, 196-197.

${ }^{35}$ Singer, 1999, 685 .

${ }^{36}$ RS 17.368, Nougayrol, 1956, 76-77. Bu belge genellikle II.Muršili dönemine tarihlenmektedir. Singer, 1999, 685 dn.271.

${ }^{37}$ uriyanni-: kuşfalı; Friedrich, 1952, 235. Bu fal türü hakkında ayrıntılı bilgi için bkz. Beal, 2002, 57-81; Ünal, 1998, 112-118; Durand, 1997, 273-282; Ünal, 1973, 129-132.

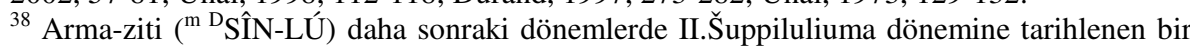
belgede 'tapri- adamlarının şefi' olarak görülmektedir. (KUB XXI 7 III 3', 5') Buradaki Arma-ziti'nin, III.Hattušili ve IV.Tudhaliya döneminde görev yapan Arma-ziti ile özdeşleştirilmesi şüphelidir. Singer, 1999, 685 dn. 269.

${ }^{39}$ Imparati, 1988, 84-86.
} 
Yukarıda ele aldığımız belgeler dışında, Arma-ziti'nin adının yer aldığı ve birbiriyle ilişkili iki dava belgesi de ayrı bir önem teşkil etmektedir. ${ }^{40}$ İlk belgede Arma-ziti, Ugarit kraliçesinin tüccarı Pušku ile gümrük görevlisi (mākisu) ya da vergi toplayıcısı Aballā arasındaki bir davada yargıç olarak görev yaparken mâr šarri unvanını kullandığını görüyoruz. İlgili pasajın tercümesi şöyledir :

RS $17.314^{41}$

1 Mâr šarri Arma-ziti'nin huzurunda

2 Gümrük görevlisi Aballa,

3-4 Ugarit ülkesi kraliçesinin tüccarı Pušku'yu yakaladı.

5-6 "Şu anda bana 300 gümüş borçlusun"

7 Ugarit ülkesi kraliçesinin tüccarı Pušku

8 (cevap verdi): "Halihazırda ben sana borçlu değilim"

İkinci belgede ise, mâr šarri Arma-ziti’nin bizzat kendisi suçlanmakta ve Ugarit kralına ve Mušrana'nın oğullarına 300 gümüş ödemesi hükmü verilmektedir. İlgili pasajın tercümesi şöyledir :

RS $17.316^{42}$

1' M[ušrana]'nın oğ[ullarına]

$2^{\prime} \quad$ ve onların oğullarına, [onların] torun[larına

3' 300 gümüşü ödeyec[ek (olan)

4' Arma-ziti, Ugar[it] kralı[na ve

5' Mušrana'nın oğullarına

6' şikayette bulunmayacak!

Arma-ziti'nin, Ugarit kralı ve Mušrana isimli şahsın oğullarına 300 šekel gümüş ödemeğe mahkum edilmiş olması; burada idari nitelikli bir görevin suiistimal edilmesi ile ilişkili ceza veya bedel olarak nitelendirilebilecek bir durumun söz konusu olabileceğini akla getirmektedir. ${ }^{43}$ Eldeki mevcut veriler, Arma-ziti'nin bir şekilde doğrudan Ugarit kralını ilgilendiren bir suiistimali gerçekleştirmiş olduğunu göstermektedir. $\mathrm{Bu}$ ve buna benzer başka belgeler, idari bölgelerin başına getirilen Hititli asilzadelerin kendi çıkarları doğrultusunda suçlar işleyebildiklerini; görevlerini kötüye kullandıklarını, keyfi olarak bir takım vergiler koyabildiklerini veya toprak parçaları başta olmak üzere bir takım mallara el koyabildiklerini bize göstermektedir. ${ }^{44}$

${ }^{40}$ RS 17.314, Nougayrol, 1956, 189; RS 17.316, Nougayrol, 1956, 190.

${ }^{41}$ RS 17.314, Nougayrol, 1956, 189.

${ }^{42}$ RS 17.316, Nougayrol, 1956, 190.

${ }^{43}$ Imparati, 1987, 199.

${ }^{44}$ Imparati, 1987, 199. 
Belgenin devamında verilen bu karara şahitlik eden şahısların isimleri sayılır. Dört tanığın hepsi de Hitit kralının tüccarları, Ura kenti vatandaşlarıdır. İlgili kısmın tercümesi şöyledir :

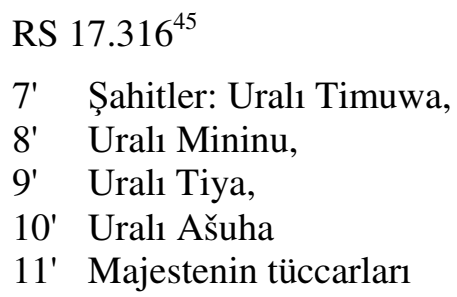

Suriye'de görevli Hitit kralının temsilcisi diğer bir mar šarri ŠukurTešub'tur. Šukur-Tešub tarafından Ugarit kralı II.Ammištamru'ya gönderilmiş bir mektup sayesinde, mar šarri 'lerin bu bölgede yürüttüğü bir başka görevi daha ögreniyoruz. Söz konusu mektubun ilk satırlarında ŠukurTešub, Hitit kralı IV.Tudhaliya'nın yanından henüz geldiğini ve Alalah kentinde (Tel Açana) beklemekte olduğunu bildirir. Belgenin ilgili kısmı şöyledir :

RS $20.03^{46}$

1-3 mar šarri Šukur-Tešub, Ugarit kenti kralı Ammištamru'ya şöyle (seslenir):

4-5 "Sana selamlar olsun! Majestenin huzurundan sana şimdi geldim ve

6-7 Alalah kentinde beklemekteyim. Sen benim sınır komşumsun.

Mektubun devamında mar šarri Šukur-Tešub, Ugarit kralına ülkesinde olup biten her şeyi kendisine bildirmesini öğütlemektedir. Kendisi de aynı şekilde davranacak ve II.Ammištamru'ya olup biten her şeyi yazacaktır. Böylelikle geçmişte yaşanan anlaşmazlıkların tekrar yaşanmaması ancak bu şekilde sağlanabilirdi. Söz konusu bölümün tercümesi ise şöyledir :

RS $20.03^{47}$

8 Sen benim ile iyi geçinmelisin.

9 Ben de seninle iyi geçinmeliyim.

${ }^{45}$ RS 17.316, Nougayrol, 1956, 190.

${ }^{46}$ RS 20.03, Nougayrol, 1968, 91-94.

${ }^{47}$ RS 20.03, Nougayrol, 1968, 91-94. 
10 Sen benim her şeyim hakkında iyi düşün.

11 Sen her şeyini bana yazacaksın,

12-13 Bende her şeyimi sana yazacağım. Beni dinleyeceksin.

Šukur-Tešub, bu mektubu Ugarit kralı II.Ammištamru'ya göndermesinin asıl sebebine ise, aşağıdaki satırlarda değinmektedir:

RS 20.03

14-17 Şimdi Paneštalı dökümcüleri sana gönderiyorum.

18-19 Hediyeleri Beletremi kentinde sunsunlar.

21-22 Sonra onları Šalmiya kenti yerel yöneticisine sunsun.

23-24 Hiç kimse onlara vergi ödetmesin.

25-27 Dağlardan gidinceye kadar onların karşısına hiç kimse çıkmasın.

28-31 Mobilyaları ve deriden yapılmış eşyaları, ihtiyaç duyulacak her şeyi Šalmiya kentinin yerel yöneticisi onlara versin.

Görüldüğü gibi bu mektup, Hitit kralına gönderilecek hediyeler ile ilgilidir. Ugarit Krallığı'nın sınırlarından çıkana kadar söz konusu hediyelerden özellikle herhangi bir vergi alınmaması konusunda ŠukurTešub, Ugarit kralı II.Ammištamru'yu uyarmaktadır. Belgelerden anlaşıldığı üzere, Hattuša sarayı tarafından Suriye'ye gönderilen mâr šarri (DUMU.LUGAL), yerel nitelikli problemleri çözmek ve merkezi yönetimin çıkarlarını korumak yanında; Ugarit ve Kargamıš'tan krala gönderilecek olan bir nevi vergi olarak tanımlayabileceğimiz malların Hattusa' ya sağlıklı bir şekilde nakil edilmesinden de sorumluydular. Burada ele almak istediğimiz bir başka mektupta da, yine bu konuya değinilmektedir. Ancak burada görevli memur bu kez sadece ismiyle anılmıştır; olasılıkla belgeyi yazıya geçiren katip, görevlinin unvanını ismin önüne eklemeyi unutmuştur. Mektubu gönderen Hišmi-kušuh isimli kişidir. Ancak diğer belgelerden farklı olarak söz konusu hititli görevli mektubunu Ugarit kralına değil, bilakis Ugarit kralının görevlendirmiş olduğu Ugarit valisine yönelik yazmıştır. Mektubun girişinde Hititli görevli Hišmi-Kušuh, Ugarit valisine saygı ve selamlarını bildirdikten hemen sonra, kendi sağlığı ile ilgili bir problemden bahseder. Ancak onu Ugarit'e getiren sebep sağlik problemleri değildir. Hišmi-Kušuh, Hitit sarayına bizzat büyük kralın kendisine yeni 
hediyelerin gönderilmesini istemektedir. İlgili pasaj şöyledir :

RS $15.33^{48}$

1-3 Hišmi-Kušuh, kardeşim valiye şöyle der :

4 Selamlar!

5-6 Ugarit ülkesinin bütün tanrıları sana sağlık versin.

7 Sana (daha önce) yazamadığım sağlık meselesine gelince,

8-10 ben burada beklemiyorum. Hatti ülkesinde beklemekteyim.

11-12 Şimdiye kadar sağlığım hakkında sana yaz(a)madım.

13-14 Şu anda kardeşim ile her şey yolundadır.

15 Bana yeni bir şeyler gönder!

Hišmi-Kušuh'un yukarıdaki pasajda Ugarit valisine 'kardeșim' șeklinde hitap etmesi aralarındaki ilişkinin samimiyetini gösterdiği gibi; aynı zamanda söz konusu Hititli memurun, Ugarit valisi ile eşit düzeyde olduğuna işaret etmektedir. Hišmi-Kušuh, Ugarit'ten Hitit Devleti'ne sürekli olarak vergi ve hediye akışının sağlanması noktasında, üstü kapalı bir uyarıda bulunuyor da olabilir. Nitekim mektubun devamında, Hišmi-Kušuh bir adamını bu hediyeleri alması için valiye ivedilikle yollayacağını belirtir. Ayrıca söz konusu mallar üzerinden, herhangi bir gümrük vergisi alınmaması yönünde salık vermeyi de unutmaz. İlgili kısmın tercümesi ise şöyledir :

\section{RS $15.33^{49}$}

26-28 Bir problem yapılmasın ve hiç kimse onun huzurunda paniklemesin! Herhangi bir gümrük memuru ondan hak talep etmesin !

29-31 Onu iyi bir şekilde gözetin ve ona engel teşkil etmeyin. (Bu adama yardımc1 olun.)

Ugarit kralı II.Ammištamru'dan sonra tahta çıkan Ugarit kralı Ibiranu Devri'nde, Boğazköy ile Ugarit sarayları arasında belirgin bir soğukluk yaşanmıştır. Bütün bunları Hitit kralının resmi elçisi mâr šarri Pihawalwi ${ }^{50}$ tarafından, Ugarit kralı Ibiranu'ya gönderilen bir mektuptan öğrenmekteyiz. Anlaşıldığı kadarıyla Ugarit kralı olması Hitit kralı tarafından pek iyi karşılanmayan Ibiranu, resmi olarak bu görevi yerine getirmeye

${ }^{48}$ RS 15.33, Nougayrol, 1955, 15-16.

${ }^{49}$ RS 15.33, Nougayrol, 1955, 15-16.

${ }^{50}$ Pihawalwi, diğer Hitit metinlerinde ve mühürlerinde adı geçen yazman Piha-UR.MAH ile eşleştirilmektedir. Singer, 1999, 684 dn. 264. 
başladığından beri büyük kralın huzuruna çıkmadığı için azarlanmaktadır. Ugarit kralı Ibiranu, verilmesi zorunlu hediyelerle birlikte bir haberci dahi göndermediği için IV.Tudhaliya'nın öfkesine maruz kalmıştır. Mektupta mâr šarri Pihawalwi, Ibiranu'yu sert bir dille uyarmakta ve Hitit kralının öfkesinin dinmesi için bir an önce ihmal ettiği görevlerini yerine getirmesini istemektedir. Söz konusu pasaj şöyledir:

RS $17.247^{51}$

1-3 mar šarri Pihawalwi oğlum Ibiranu'ya şöyle (der):

4 Burada majeste için her şey

5 yolundadır.

6-9 Majestemin desteğiyle Ugarit Ülkesi Krallığı'nı sen ele geçirdikten sonra majesteye niçin gelmedin?

10 Üstelik sen kendi elçilerini

11 şimdiye kadar göndermedin.

12-13 Bundan dolayı halihazırda

14-15 Majestem çok sinirlidir.

16-17 Hemen çok hızlı bir biçimde (hiç vakit kaybetmeden) elçilerini

18-20 majesteye yolla ve (onlar) kralımın hediyelerini, benim hediyelerim ile birlikte buraya taşısınlar !

Son derece kritik görevleri üstlenmiş mâr šarri'ler (DUMU.LUGAL), yukarıdaki belgeden de gayet net bir şekilde anlaşılacağı üzere gerektiğinde büyük kralın emirlerini bir vassal krala oldukça sert bir üslupta söyleme özgürlüğüne sahiptirler. mâr šarri’ler (DUMU.LUGAL) yeri geldiğinde bir vassal kraldan bile üstün konumda olabiliyorlardı. Kușkusuz mâr šarri'lerin (DUMU.LUGAL) görev tanımlamaları bizzat Hitit kralı tarafından yapılmıştır. Söz konusu unvanı taşıyan görevlilerin görev yaptıkları bölge sınırları içinde Hitit Devleti tarafından gerçekleştirilen seferlerde herhangi bir askeri yetkileri olduğuna dair bir bilgiye sahip değiliz.

Sonuç olarak mâr šarri'lerin (DUMU.LUGAL) yukarıda ele aldığımız mektuplarda gönderici hanesinde gözükmelerine, gidecekleri yerler kendilerine çok önceden haber verilmesine veya Ugarit gibi Hitit hakimiyeti altında bulunan vassal krallıklarda gerçekleştirmiş oldukları faaliyetlerden bahsedilmiş olmasına rağmen yine de onların hakiki prens olmalarının

${ }^{51}$ RS 17.247, Nougayrol, 1956, 191; Malbran-Mabat, 1991, 48. 
imkansız olduğunu düşünüyoruz. Burada tamamıyla resmi bir görevliden bahsedilmektedir. Ayrıca söz konusu memurların, doğrudan Kargamıš kralına bağlı olarak görev yaptığını iddia etmenin oldukça güç olduğuna inanıyoruz. Daha önce de ifade ettiğimiz gibi Kargamıš, Ugarit ve Emar gibi krallıklara gönderilen mâr šarri'ler (DUMU.LUGAL), buralarda Hitit merkezi otoritesinin adına üstlenmiş oldukları idari ve temsili nitelikli görevleri yerine getirmekteydiler.

İmparatorluğun büyümesi ile birlikte bu kimselerin görev sahalarının genişlediği ve böylelikle bu görevlilerin devlet olanaklarını kendi çıkarlarına kullanmalarına olanak sağlayan bir ortamın ortaya çıktığı görülmektedir. ${ }^{52}$ Yukarıda ele aldığımız belgeler de büyük Hitit kralının kendisine verdiği yetkiyi ve güveni kendi çıkarları doğrultusunda kullanan mâr šarri'lerden (DUMU.LUGAL) bahsedilmektedir. Görevini suistimal eden söz konusu görevlilerin bir dava sürecine dahil edilerek yargılanması; Kargamıš krallarının, Hitit kralı adına hareket etmek suretiyle Hitit Devleti'nin hakimiyeti altındaki diğer Suriye vassal krallıklarında da görev yapan mâr šarri'leri kontrol altında tutma gibi bir fonksiyona sahip olduklarını bize göstermektedir. $\mathrm{Bu}$ aynı zamanda vassal krallıklarda uygulanan idari sistemin son derece kompleks bir yapıya sahip olduğuna işaret etmektedir.

\section{2. ${ }^{\text {LÚ }}$ kartappu ve Görevleri}

Suriye'de kurulan Hitit idari sisteminin yürütücüsü bir diğer üst düzey memur ise ${ }^{\text {LÚ }}$ kartappu'dur. ${ }^{\text {LÚ }}$ kartappu'luk müessesinin aslında yerel idarede oldukça önemli bir pozisyonu bulunmaktaydı. kartappu- sümerce $\mathrm{kir}_{4} . d a b$ "yem torbasını tutan kişı”, "at dizgini” anlamlarına gelen sözcükten türetilmiştir. ${ }^{53}$ LÚ kartappu ise "seyis", "araba sürücüsü" anlamlarına gelmektedir. ${ }^{54}$ Çoğunlukla Amarna ve Boğazköy belgelerinde ${ }^{55}$ rastladığımız ${ }_{\mathrm{LU}}$ kartappu önceleri seyis ve arabacıları denetlemenin yanı sıra kral ailesine ve kısmen de kralın kendisine hizmet eden resmi bir görevliydi. Söz konusu görevliler saraydaki yetenekli görevliler arasından ya da bizzat saray

52 Imparati, 1987, 199.

${ }^{53}$ Hitit belgelerinde geçen ${ }^{\text {Lú }}$ kartappu için bkz. Daddi, 1977, 169-191; Singer, 1983, 9.

54 LÚ kartappu: Bir prensin ahırlarına ve onlarla ilgili gereçlere bakmakla görevli kimse, araba sürücüsü”, Friedrich, 1952, 311.

${ }^{55}$ KBo IV 14 III 47; KBo XII 135 VI 2-14; KBo XIII 253 Rs. 1'; KBo XIV 142 IV 14; KBo XVIII 4; KBo XXII 218 Rs. 4'; KUB V 3 I 9, [34] (?); KUB V 4 + KUB XVIII 53 II 37; KUB XIII 35 II 43; KUB XIV 3 II 58, 59, 70, 72; KUB XVI 19 I 6'; KUB XIX 18 I 23'; KUB XXI 29 II 7, 9; KUB XXI 38 Rs. 22'; KUB XXII 1 Vs 4' [ ]??; KUB XXX 24 I 9; KUB XXXI 68 (Vs.) 39'; KUB XXXI 71 III 5'; KUB XL 20 Rs. 1, 6; KUB XLII 34 Rs. 11'; IBoT I 36 IV 24; VBoT 128 V 12'; Daddi, 1977, 190; Daddi, 1982, 133. 
ailesindeki kişiler arasından seçiliyordu. Hitit unvanları zaman içinde önemli değişikliklere uğramaktaydı. ${ }^{56}{ }^{L U}$ kartappu unvanının sorumluluk alanı da zaman içinde önemli değişikliklere uğramıştır.

M.Ö.13.yüzyılda Hititler'in dış ilişkilerinin yoğunlaşması ve özellikle Suriye'deki vassal krallar ile Hitit kralı arasındaki ilişkilerin artmasıyla birlikte ${ }^{\text {LÚ }}$ kartappu'nun görev sahası da genişlemiştir. ${ }^{57}$ Kral ailesine ve bizzat krala yakın olan ${ }^{\text {Lú }}$ kartappu, Suriye krallıkları ve Hitit Devleti arasında diplomatik bir misyon üstlenmiştir. ${ }^{58} \mathrm{Bu}$ bir gereksinmeden ortaya çıkmıştır. IV.Tudhaliya'nın Suriye'deki vassal krallıkları arasında Hitit yönetim mekanizmasının idari, askeri ve hukuki bakımdan hızlı bir şekilde işlemesini sağlamak için bu tür görevlilere büyük ihtiyaç vardı. ${ }^{L U}$ kartappu ve yukarıda ele aldığımız mâr šarri gibi görevliler sayesinde Hitit Devleti Suriye'de, başkent Hattuša' da olduğu gibi etkili bir idari sistemin kurulmasını sağlamıştır.

Ugarit'te (Ras-Şamra) ele geçen belgeler ${ }^{59}{ }^{L U^{\prime}}$ kartappu'nun sadece saraylar arasında haber götürüp getirmekle görevli kimseler olmadığını göstermektedir. Çünkü zaten tēmu ve mar šipri gibi görevliler mesaj ve haber taşımakla görevliydiler. Ancak ${ }^{L U}$ kartappu unvanını taşıyan kişiler, çok önemli ve karmaşık bir dizi diplomatik misyonu yerine getirmekle yükümlüydüler. Aynı zamanda söz konusu görevliler, Hitit kralının Suriye politikası konusunda onu yönlendiren ve ona danışmanlık yapan kimselerdir. Belgelerden anlaşıldığına göre, ${ }^{L}{ }^{k}$ kartappu sadece Hattuša ve Kargamıš saraylarında var olan bir müessese değildi. Vassal krallıklarda da görev yapan ${ }^{L U}$ kartappu'lar vardı. Ancak bu ${ }^{L U}$ kartappu'lar bağlı bulundukları vassal kralın çıkarları doğrultusunda görev yapmaktaydılar. ${ }^{60}$

Ugarit'te (Ras-Şamra) ele geçen akadca çivi yazılı belgelerin bir kısmında ${ }^{L U}$ kartappu unvanını taşıyan kişilerin isimleri de yer almaktadır. ${ }^{61}$ $\mathrm{Bu}$ isimlerden bazıları şunlardır: ${ }^{\mathrm{m}} \mathrm{Hawa}-\mathrm{Il}$ (RS 8.213, 32), ${ }^{\mathrm{m}}$ Yaraziti (RS 17.137, 5'), 'Kila'e (RS 19.70, 3; RS 17.112, 2), 'Šunailu (RS 17.244, 4), ${ }^{\mathrm{m}}$ Takhulinu (RS 16.273, 2), ${ }^{\mathrm{m}}$ Talmi-Tešub (Rs. 17.289, 6), ${ }^{\mathrm{m}}$ Zuzzullu (RS

\footnotetext{
${ }^{56}$ GAL GEŠTIN unvanının anlamında da aynı şekilde değişiklikler olmuştur. Singer, 1983, 9.

${ }^{57}$ Singer, 1983, 9.

${ }^{58}$ Singer, 1983,9 vd.

${ }^{59}$ RS 8.213, 32; RS 15.19, 5; RS 16.273, 2-3; RS 17.112, 2-4; RS 17.137, 5'; RS 17.244, 4-6; RS 17.252, Vs. 21'; Rs. 17.289, 6-7; RS 18.20+17.371, Rs. 2-3; RS 11.732, RS 19.70, 3. Ayrıntılı bilgi için bkz. Daddi, 1977, 190.

${ }^{60}$ RS 15.19, Nougayrol, 1955, 13'de küçük bir krallık olan Barga vassal krallığının, Ugarit Krallığı'na bir ${ }^{L U}$ kartappu gönderdiği ifade edilir. Singer, 1983, 11.

${ }^{61}$ Daddi, 1977, 191.
} 
18.20+17.371, Rs. 1, 2, Vs. 6). Ugarit (Ras-Şamra) belgelerinde yer alan ${ }^{L U}$ kartappu unvanını taşıyan kişi isimlerinin, Hititce çivi yazılı Boğazköy geçen ${ }^{L U}$ kartappu isimlerinden farklı olduğu ilk bakışta göze çarpmaktadır ${ }^{62}$ : ${ }^{\mathrm{m}}$ Karia (KBo XIV 142 IV 14), ${ }^{\mathrm{m}}$ Dabalad ${ }^{\mathrm{d}} \mathrm{U}$ (KUB XIV 3 II 57, 58), ${ }^{\mathrm{m}} \mathrm{Zuzu}$ (KUB XXI 38 Rs. 22), m AMAR.MUŠEN (KUB XIII 35 II 43).

Şimdi ele alacağımız ve Kargamıš kralı tarafından Ugarit kralına gönderilen söz konusu mektupta, Hitit Sarayı'ndan Ugarit'e gönderilen ${ }^{L U}$ kartappu'nun yapacağ 1 askeri teftişten bahsedilmektedir. $\mathrm{Bu}$ teftiş esnasında Ugarit Krallığı'nın askeri birlikleri ve arabaları denetlenecektir. Söz konusu mektubun ilgili kısmının tercümesi şöyledir :

RS $17.289^{63}$

1-3 Kargamıš kralı Ugarit kralı Ibiranu'ya şöyle (der):

\section{4-5 Selamlar!}

6-8 Sana şimdi majestemin kartappusu Talmi-Tešub gelecek.

9 Senin askerlerini ve savaş arabalarını görecek.

10-14 Saraydan sana ne kadar asker ve savaş arabası göndereceğini görmeye gelecek.

Söz konusu belgeye göre Kargamıš kralı, asker ve arabaların sayısının büyük kralın taleplerine uygun olup olmadığını belirlemek için Hitit kralının kartappusu Talmi-Tešub'un (GAL- $\left.{ }^{\mathrm{d}} \mathrm{IM}\right)^{64} \mathrm{Ugarit}^{\prime}$ 'e geleceğini bildirmektedir. Sonrasında Kargamıš kralı, Ugarit kralının bu teftiş olayına herhangi bir müdahalede bulunmamasını istemektedir. Aksi halde majestenin bundan huzursuz olacağ 1 yönünde bir ifade kullanan Kargamıš kralı mektubunu "Bu bir ölüm ve kalım meselesidir"65 şeklinde oldukça dramatik bir ifadeyle bitirmektedir. Mektubun bu bölümü şöyledir :

${ }^{62}$ Daddi, 1982, 134.

${ }^{63}$ RS 17.289, Nougayrol, 1956, 192.

${ }^{64}$ Lipiński, 1981, 89, dn.53'de söz konusu kartappu'nun geleceğin Kargamıš kralı İniTešub'un oğlu Talmi-Tešub ile özdeş olabileceği yönünde bir görüş bildirmiştir. Ancak kronolojik olarak bu eşitlik mümkün olsa da bu bilgiyi destekleyecek bir başka belge olmadığı için, iki kişinin ayrı tutulması bizce daha doğru olacaktır. Nitekim, Imparati, 1987, 201'de o zaman veliaht olan geleceğin Kargamıš kralı Talmi Tešub'un, bir vassal devletin kralına bu şekilde takdim edilmiş olmasının, pek uygun düşmediğinin altını çizmektedir.

${ }^{65}$ Aynı ünlem, majestesinin Ugarit kralına hububat yüklü gemileri acil olarak göndermesini emrettiği RS 20.121'de de (Schaeffer, 1956, no. 33) tekrarlanmaktadır. Singer, 1999, 716. 
RS $17.289^{66}$

15-16 Ona izin ver ki majestem bunun hesabını yapacak.

17-19 Majestem hiçbir şekilde huzursuz olmasın!

20 İş ciddi(dir.) (Bu bir ölüm ve kalım meselesidir).

İpuçları göz önünde bulundurulduğunda başka birkaç belge ${ }^{67}$ aynı olayla ilişkili olabilir. ${ }^{68}$ H.Klengel, bu belgeler arasında askeri faaliyetlerle ilgili bilgi veren bir tablet parçasının bu mektuba ait olduğunu iddia etmektedir. ${ }^{69}$ Klengel, gönderici hanesinde gözüken kralın Kargamıš kralı olduğuna hiç şüphe olmadığını ve mektubun alıcısı olan kişinin de Ugarit kralı Ibiranu olabileceği yönünde bir tahmin yürütmüştür. Oldukça kırık durumdaki tabletin içeriğinden anlaşıldığ 1 kadarıyla burada, Hitit büyük kralı tarafından talep edilen askeri birlikler ile ilişkili bir konu ele alınmaktadır. Savaş arabası ve piyade birliklerinin gönderilmesinden dolayı, Ugarit kralının öfkelenmiş olduğu açıkça görülmektedir. Mektubu Kargamıš kralı, 'Majestene git' emriyle bitirmektedir.

Bir başka fragmanda ise Ugarit kralı I[biranu?], Kargamıš kralının istemiş olduğu 1600 tane ok destesini habercisi Ahaltena ile göndermiş olduğunu rapor etmiştir. ${ }^{70}$ Yine çok küçük bir fragmanda ise, Ugarit kralı Ibiranu ve 300 askerden söz edilmektedir. ${ }^{71}$ Majestenin diğer bir kartappu'su olan (Hé-r[u-?)'nun yollanacağı ise, Kargamı̌̌ kralının bir başka mektubunda bildirilmektedir. ${ }^{72}$ Ancak belgenin neredeyse yarısı tahrip olduğundan söz konusu fragmandan başka herhangi bir bilgi elde edilememektedir.

Başka askeri konular hakkında da, Kargamıš kralının Ugarit kralı Ibiranu'ya mektupları vardır. ${ }^{73}$ Genel olarak Kargamıš kralının mektupları, Ibiranu'nun çok güvenilir olmayan bir vassal olarak değerlendirildiğini bize

\footnotetext{
${ }^{66}$ RS 17.289, Nougayrol, 1956, 192.

${ }^{67} \mathrm{Bu}$ belgelerin tarihlendirilmesi hususunda bkz. Yamada, 1992, 444.

${ }^{68} \mathrm{Bu}$ fragmanlar oldukça kırıklı oldukları için, çalışmamızda tercümelerine yer verilmemiştir.

${ }^{69}$ RS 20.237 , Schaeffer, 1956, 102-105. Yorumlar için bkz. Klengel, 1975, 61.

${ }^{70}$ RS 15.014, Nougayrol, 1955, 5.

${ }^{71}$ RS 17.018, Nougayrol, 1956, 195.

${ }^{72}$ RS 34.138, Bordreuil, 1991, No.8.

${ }^{73}$ RS 17.243, Nougayrol, 1956, 193'de Prens Mišramuwa'nın Ugarit'te kalmak için gittiği yerde iyi karşılanmış olduğu bildirilmektedir. RS 17.385, Nougayrol, 1956, 194'de ise, Ugarit'ten sabit uzunluk ve kalınlıkta ardıç keresteleri talep edilmektedir. Klengel, 1992, 146 dn. 331 ve dn. 332 .
} 
açıkça göstermektedir. ${ }^{74}$ Bu belgeler, Kargamıš Krallığı'nın özellikle askeri konularda Ugarit'i sürekli kontrol altında tuttuğu izlenimi vermektedir. Tüm bu gelişmeler belki de bölgede Asur ordularına karşı yapılacak yeni bir savaşın hazırlıkları da olabilir. Birçok bilim adamı, Ugarit'te bulunan söz konusu belgeleri, bir kriz dönemine tarihlendirme konusunda oldukça ısrarcı davranmıştır. ${ }^{75}$ Yukarıda ifade ettiğimiz gibi, Hitit kralı adına hareket ettiği anlaşılan Kargamıš kralı, Ugarit kralına "ölüm kalım” meselesi olarak nitelediği bir gelişmeden ötürü piyade ve savaş arabası birlikleri yollamasını emretmektedir. Belki de tüm bu hazırlıklar, Asur ve Hitit Devleti arasında gerçekleşen Nihriya Savaşı öncesi bölgede yaşanan savaş öncesi Hitit vasallerinin durumunu yansitmaktadır.

Görüldüğü gibi, IV.Tudhaliya Kargamıš’ta bürokratik işlemleri kendisi olmadan da yürütebilecek donanımda olduğu anlaşılan DUMU.LUGAL (mâr šarri) ve ${ }^{L U}$ kartappu'lar sayesinde, Suriye'de Hitit idari sistemine benzer yapıda bir idari yapı tesis etmeyi başarmıştır. Söz konusu memurlardan mâr šarri’ler ( DUMU.LUGAL) bazen bir davada yargıç, şahit ya da noter iken; bazı durumlarda ise, Hitit kralı ile vassal kralıklar arasında elçilik yaparken karşımıza çıkmaktadır. Aynı durum, farklı görev tanımlamaları için de ${ }^{L U}$ kartappu'lar içinde geçerliydi. ${ }^{L U}$ kartappu'lar; daha öncede bahsettiğimiz gibi vassal krallıklarda bulunan Hitit krallığına ait askeri kuvvetleri denetlemek, Hitit Devleti ile vassal krallıklar arasında güvenli bir haberleşmeyi sağlamak ve Hitit kralına Suriye politikası konusunda danışmanlık yapmak gibi birbirinden çok farklı görevleri yerine getirmekteydiler.

Ancak yukarıda ele aldığımız RS $17.247^{76}$ numaralı belgeden de anlaşılacağı üzere, II.Ammišstamru'dan sonra tahta oturan Ugarit kralı Ibiranu döneminde Boğazköy ile Ugarit sarayları arasında yaşanan soğukluk; Hititlerin M.Ö. 13. yüzyılın başından itibaren Kargamıš’ta oluşturdukları ve Suriye'de Hititler' in hakimiyeti altındaki toprakların büyük bölümüne hükmeden merkezileşmiş idari sistemin artık eskisi gibi işlemediğini bize göstermektedir. Bütün bu süre zarfında sağlıklı bir şekilde işleyen bu yönetim mekanizmasının birdenbire bozulması, Hitit Devleti'nin Kuzey Suriye'deki nüfuzunun gittikçe zayıfladığını düşünmemize neden olmaktadır. Doğu cephesinde gün geçtikçe büyüyen Asur tehditi ${ }^{77}$ ve

\footnotetext{
${ }^{74}$ Klengel, 1992, 146.

${ }^{75}$ Otten, 1959, 68; Harrak, 1987, 259-260.

${ }^{76}$ Nougayrol, 1956, 191; Malbran-Mabat, 1991, 48.

77 Asur kralı I.Tukulti-Ninurta, Hitit Devleti'nin Suriye'de kurduğu siyasi hakimiyetten bir hayli rahatsızdır. Hititler'in Suriye'ye hakim olarak bu bölgeyi tamamen ele geçirmesi, Asur'un siyasi ve ekonomik çıkarlarına tamamen ters düşmekteydi. En büyük hayali batıdaki
} 
ülkedeki karışık hanedan problemleriyle ${ }^{78}$ birlikte IV.Tudhaliya ve temsilcilerinin sabırsılıkları, Ugarit kralı Ibiranu'nun iddialı tavırları ve işbirliğinden kaçınmasıyla çok daha fazla büyümüştür. ${ }^{79} \mathrm{Bu}$ sebeple, IV.Tudhaliya'nın Suriye'de bulunan krallıklara yönelik uyguladığı dış politika bu dönemde değişikliğe uğramıştır. Büyük Hitit kralı, Kuzey Suriye ile olan ilişkilerini belki eskisine oranla daha sert ve kesin bir tavırla sürdürmeye karar vermiştir. Bu tavrın altında yatan esas neden ise, bölgedeki krali gücün sağlamlaştırılmasıdır. Ancak Suriye politikasında uygulanan tüm bu sert politikalara ve askeri önlemlere rağmen Hitit Devleti'nin Suriye'de temelleri I.Šuppiluliuma tarafından atılan vassallik sistemi, çok büyük bir olasılıkla IV.Tudhaliya'nın hükümranlığının son yıllarında tamamen çökmüştür. Deniz ve kara ticaretinin iki önemli durağı Amurru ve Ugarit, olasılıkla bu yıllarda Hitit Devleti'nden tamamen kopmuşlardır. Hitit Devleti'ni ekonomik anlamda büyük bir sıkıntıya sokan bu durum kuşkusuz Hitit İmparatorluğu'nun dağılmasını tetikleyen en önemli nedenlerden biri olmuştur.

ticaret yollarına hakim olmak olan I.Tukulti-Ninurta'nın, bu yolda karşısına çıkan en önemli engel, Suriye' deki Kargamıš, Ugarit ve Amurru Krallıkları üzerinde sağlam bir iktidar kuran Hitit Devleti'ydi. Nitekim Asur ve Hitit Devletleri arasında gün geçtikçe büyüyen gerginlik Nihriya yakınlarında bir savaşa yol açmıştır. Nihriya Savaşı hakkındaki bilgileri Asur kralının Ugarit kralına göndermiş olduğu rapor niteliğindeki bir mektuptan (RS 34.165) öğreniyoruz. Mektupta Asur kralı, Nihriya yakınlarında Hitit birliklerine karşı bir zafer kazandığından bahsetmektedir. Asur kralı, Ugarit kralına Hititler'e karşı kazandıkları zaferin kayıtlarını göndermiş; ayrıca yapılan çatışmanın hem askeri gerekçesi hem de yasal dayanağı ve ahlaki anlamına da aynı belge içinde yer vermiştir. Gerek söz konusu mektubu gönderen Asur kralının, gerekse alıcı konumundaki Ugarit kralının isimleri tabletin oldukça zarar görmüş kısımlarında yer aldığından, bu konuda sağlıklı bir yorumda bulunabilmek mümkün değildir. İşte bu yüzden, bu belgenin tarihlendirilmesi konusunda tam bir antlaşma sağlanabilmiş değildir. Konu hakkında detaylı bilgi için bkz. Taş, 2007, 74-87; Dietrich, 2003, 103-139; Lackenbacher, 1982, 141-151.

${ }^{78}$ Boğazköy III numaralı tapınakta bulunan bir mühür üzerinde "Güneşim (Majestem) Büyük Kral Labarna Kurunta" ifadesi okunmaktadır. (van den Hout, 1995, 18; Otten, 1989, 14 vd; Neve, 1992, 315.) Bu mührün Hattuša'da bulunması, birçok araştırmacı tarafından, Kurunta'nın geçici bir süre Hattuša'yı işgal ettiği şeklinde yorumlanmıştır. Konu hakkında ayrıntılı bilgi ve bibliyografya için bkz. Taş, 2007b, 25-26.

${ }^{79}$ Singer, 1999, 683-684. 


\section{Kaynakça ve Kısaltmalar}

ALP, S., 1947, "Hitit Kralı IV.(?) Tuthaliia'nın Askeri Fermanı", Belleten 43, 383416.

BEAL, R.H., 2002, "Hittite Oracles", L.Ciraola-J.Seidel (ed.), Magic and Divination in the Ancient Worlds, Brill, 57-81.

BECKMAN, G., 1992, "Hittite Administration in Syria in the light of the Texts from Hattusa, Ugarit and Emar", New Horizons in the Study of Ancient Syria. Bibliotheca Mesopotamica 25, M.W.Chawalas-J.L.Hayes (ed.), Malibu, 41-49.

BECKMAN, G., 1995, "Hittite Provincial Administration in Anatolia and Syria: the View from Maşat and Emar", Atti Del II Congresso Internazionale di Hittitologia, Studia Mediterranea IX, O.Carruba-M.Giorgieri-C.Mora, (ed.), Pavia, 19-37.

BORDREUIL, P., ARNAUD, D. ve diğerleri, 1991, "Une bibliothèque au sud de la ville. Les textes de la 34' campagne (1973)", Paris.

BRYCE, T., 2003, Letters of the Great Kings of the Ancient Near East The Royal Correspondence of the Late Bronze Age, New York.

CTH : Catalogue des Textes Hittites.

DADDI, F.P., 1975, "Il HAZAN(N)U nei testi di Hattusa", Oriens Antiquus 14, 93136.

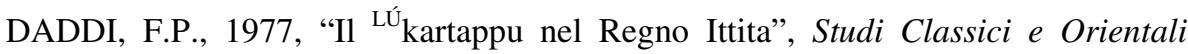
XXVII, Pisa, 169-191.

DADDI, F.P., 1982, Mestieri, Professioni e Dignità nell'Anatolia ittita, Roma.

D'ALFONSO, L., 2001, "Further Studies on the Ini-Tešub Sealing", Altorientalische Forschungen 28, 267-275.

del MONTE, G.F.- TISCHLER, J., 1978, Répertoire Géographique des Textes Cunéiformes VI. Die Orts und Gewässernamen der hethitischen Texte, Wiesbaden.

del MONTE, G.F., 1992, Répertoire Géographique des Textes Cunéiformes VI/2. Die Orts und Gewässernamen der hethitischen Texte. Supplement, Wiesbaden.

DIETRICH, M., 2003, "Salmanassar I. von Assyrien, Ibiranu (VI.) von Ugarit und Tuthalija IV. von Hatti. RS 34.165 und die Schlacht von Nihrija zwischen den Hethitern und Assyrern", Ugarit-Forschungen. Internationales Jahrbuch für die Altertumskunde Syrien-Palästines XXXV, 103-139.

dn. Dipnot

DROWER, M.S., 1968, "Ugarit. Ugarit in the Fourteenth and Thirteenth Centuries B.C.", The Cambridge Ancient History, Revised edition of Volume II, Part 2, Chapter XXI (b), Cambridge, 1-19.

DURAND, J.-M., 1997, “La divination les oiseaux”, MARI 8, 273-282. 
FRIEDRICH, J., 1952, Hethitisches Wörterbuch. Kurzgefasste kritische Sammlung der deutungen hethitischer wörter, Heidelberg.

GOETZE, A., 1950, "Hittite Instructions", J.B. Pritchard (ed.), Ancient Near Eastern texts relating to the Old Testament, 207-210.

GUTERBOCK, H.G.- van den HOUT, T.P.H, 1991, The Hittite Instruction for the Royal Bodyguard.

HARRAK, A., 1987, Assyria and Hanigalbat. A Historical Reconstruction of Bilateral Relations from the Middle of the Fourteenth to the End of the Twelfth Centuries B.C., Texte und Studien zur Orientalistik, Band 4, HildesheimZürich-New York.

HAWKINS, J. D., 1980, "Karkamiš", Reallexikon der Assyriologie V/5-6, 426-446.

IMPARATI, F., 1974, "Una concessione di terre da parte di Tudhaliya IV", Revue Hittite et Asianique XXXII, 1-208.

IMPARATI, F., 1975, “' 'Signori' e 'figli del re' ”, Orientalia. Nova Series 44, 8095.

IMPARATI, F., 1983, "Aspects de l'organisation de l'état Hittite dans les documents juridiques et administratifs", Journal of Economic and Social History of the Orient 25, 225-267.

IMPARATI, F., 1987, "La politique extérieure des Hittites: tendances et problèmes", Hethitica VIII, Acta Anatolica. (Colloque Anatolian, Paris, 1985), R.Lebrun (ed.), 187-207.

IMPARATI, F., 1988, "Armaziti: attività di un personaggio nel tardo impero ittita", F.Imparati (ed.), Studi di storia e di filologia anatolica dedicati a Giovanni Pugliese Carratelli, 79-94.

JACOB-ROST, L., 1965, "Beiträge zum hethitischen Hofzeremoniell (IBoT I 36)" Mitteilungen des Instituts für Orientforschung 11, 165-225.

KLENGEL, H., 1965, Geschichte Syriens im 2.Jahrtausend v.u.Z. I, Berlin.

KLENGEL, H., 1975, "Neue Quellen zur Geschichte Nordsyriens im 2. Jahrtausend v.u.Z.", Altorientalische Forschungen 2, 47-64.

KLENGEL, H., 1992, Syria 3000 to 300 B.C. A Handbook of Political History, Berlin.

KBo Keilschrifttexte aus Boğazköi. Leipzig/Berlin, 1919 vd.

KUB Keilschrifturkunden aus Boghazköi, Berlin 1921 vd.

LACKENBACHER, S., 1982, “Nouveaux Documents D'Ugarit-Une Lettre Royale", Revue d'Assyriologie et d'Archéologie Orientale 76, 141-156.

LIPIŃSKI, E., 1981, "Ahat-milki, reine d'Ugarit, et la guerre du Mukiš", Orientalia Loveniensia Periodica 12, 79-115. 
LIVERANI, M., 1960, "Kargamış Nei Testi di Ugarit", Rivista de Studi Orientali 35, 135-147.

MCMAHON, G., 1997, The Context of Scripture 1, W.W.Hallo (ed.), 217-221.

MALBRAN-LABAT, F., 1991, "Listes", Une bibliothèque au sud de la ville. Les textes de la 34' campagne (1973), P.Bordreuil ve diğerleri (ed.), Paris, 17-26.

NEVE, P., 1992, "Die Ausgrabungen in Boğazköy-Hattusa 1991”, Archäologischer Anzeiger III, 307-338.

NOUGAYROL, J., 1955, Le Palais Royal D'Ugarit III. Textes accadiens et hourrites des archives est, quest et centrales. Mission de Ras Shamra VI, Paris.

NOUGAYROL, J., 1956, Le Palais Royal D'Ugarit IV. Textes accadiens des archives sud. Mission de Ras Shamra IX, Paris.

NOUGAYROL, J. - LAROCHE, E. - VIROLLEAUD, C.- SCHAEFFER - C.F.-A., 1968, Ugaritica V. Nouveaux textes accadiens, hourrities et ugaritiques de Archives et Bibliothèques privées d'Ugarit. Commentaires des textes historiques, Paris.

RS Ras Şamra.

OTTEN, H., 1959, "Korrespondenz mit Tukulti-Ninurta I. aus Boğazköy", E.Weidner (ed.), Die Inschriften Tukulti-Ninurtas I. und seiner Nachfolger. Archiv für Orientforschung. Internationale Zeitschrift für die Wissenschaft vom Vorderen Orient Beiheft 12, Graz, 64-68.

OTTEN, H., 1964, "Aufgaben eines Bürgermeisters in Hattusa", Baghdather Mitteilungen 3, 91-95.

OTTEN, H., 1989, Die 1986 in Boğazköy gefundene Bronzetafel. Zwei Vorträge, Wiesbaden.

REYHAN, E., 1994, Hitit İdari Sisteminde Yer Alan Yönetim Görevlileri, (Ankara Üniversitesi, Yayınlanmamış Yüksek Lisans Tezi)

RS Ras Şamra

SCHAEFFER, C.F.-A., 1956, Ugaritica III. Sceaux et cylindres hittites, épée gravée $d u$ cartouche de Mineptah, tablettes chypro-minoennes et autres découvertes nouvelles de Ras Shamra, Paris.

SINGER, I., 1983, "Takuhlinu and Haya : Two governors in the Ugarit Letter from Tel Aphek", Tel Aviv 10, 3-25

SINGER, I., 1999, "A Political History of Ugarit", Handbook of Ugaritic Studies. W.G.E. Watson ve N. Wyatt (ed.), Handbuch der Orientalistik, Abt. 1, Der Nahe und Mittlere Osten. Band 39, Leiden, Boston, Köln.

st. satır

STARKE, F., 1996, "Zur 'Regierung' des hethitischen Staates", Zeitschrift für Altorientalische und Biblische Rechtsgeschichte 2, E.Otto (ed.), Wiesbaden, 140-182. 
STARKE, F., 2001, "Karkemis, Karkamis ”, Der Neue Pauly Enzyklopadie der Antike Band 6, H.Cancik ve H.Schneider (ed.), 280-283.

STURTEVANT, E.H.-BECHTEL, B., 1935, A Hittite Chrestomaty.

SÜEL, A., 1985, Hitit Kaynaklarında Tapınak Görevlileri Ille ilgili Bir Direktif Metni, Ankara.

TAŞ, İ., 2007a, "Ugarit Kralı Ammištamru ile Amurrulu Prenses Arasındaki Boşanma Davası ve Diplomatik ve Hukuksal Sonuçları", Ş.Batmaz-H.A.Şahin (ed.), Mısır-Hitit Ebedi Barış Antlaşması (Kadeş) ve Eski Önasya'da Barış, Erciyes Üniversitesi Kapadokya Araştırma Merkezi, Nevşehir.

TAŞ, İ., 2007b, IV.Tudhaliya'nın Asur Devleti ve Suriye'deki Vassal Kralliklara Yönelik Politikası, (Ankara Üniversitesi, Yayınlanmamış Doktora Tezi)

ÜNAL, A., 1973, "Zum Status der 'augures' bei den Hethitern", Revue Hittite et Asianique 31, 27-56.

ÜNAL, A., 1998, "Ein Vogelorakel aus Boğazköy mit pseudo-rechtlichen Bemerkungen über Familienrecht (KUB $43.22+=$ Bo 854 mit Dupl. KBo 13.71)", Altorientalische Forschungen 25, 112-118.

ÜNAL, A., 2005, Hititler Devri'nde Anadolu III. Arkeoloji ve Sanat Yayınları. Eski Anadolu Uygarlıkları Dizisi:12, İstanbul.

van den HOUT, T.P.J., 1995, Der Ulmitesub-Vertrag. Eine Prosopographische Untersuchung, StBot 38.

von SCHULER, E., 1957, Hethitische Dienstanweisungen für hohere Hof- und Staatsbeamte. Ein Beitrag zum antiken Recht Kleinasiens. Archiv für Orientforschung. Internationale Zeitschrift für die Wissenschaft vom Vorderen Orient Beiheft 10, Graz.

YAMADA, M., 1992, "Reconsidering the letters from the 'King' in the Ugarit texts: royal correspondance of Carchemish?" Ugarit-Forschungen. Internationales Jahrbuch für die Altertumskunde Syrien-Palästines 24, 431-446. 

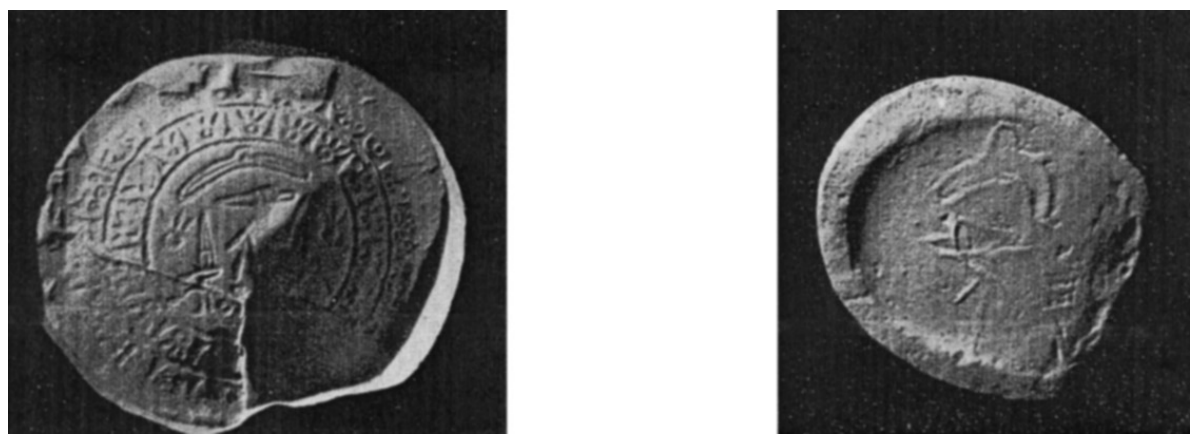

Resim 1a. mâr šarri Arma-ziti’nin mühür baskıları. Schaeffer, 1956, 38.

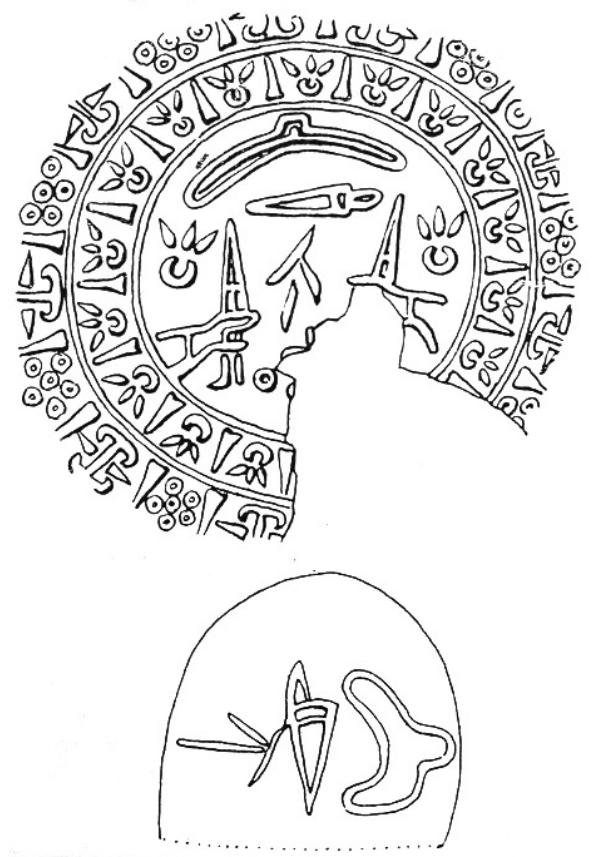

Resim 1b. Aynı mühür baskısının çizimleri. Schaeffer, 1956, 37. 
